Supporting Information (SI)

\title{
Ionic Salts@Metal-Organic Frameworks: Remarkable \\ Component to Improve Performance of Fabric Filters to Remove Particulate Matters from Air
}

\author{
Dong Kyu Yoo, ${ }^{1}$ Ho Chul Woo, ${ }^{1}$ and Sung Hwa Jhung ${ }^{*}$ \\ Department of Chemistry and Green-Nano Materials Research Center, Kyungpook National \\ University, Daegu 41566, Republic of Korea \\ *Corresponding author: Prof. Sung Hwa Jhung \\ Phone: +82-10-2818-5341; Fax: +82-53-950-6330 \\ E-mail: sung@knu.ac.kr \\ ${ }^{1}$ These authors equally contributed to this work.
}




\section{Materials}

Terephthalic acid (TPA, $\left.\mathrm{C}_{6} \mathrm{H}_{4}-1,4-\left(\mathrm{CO}_{2} \mathrm{H}\right)_{2}, 98 \%\right)$, chromium chloride $\left(\mathrm{CrCl}_{3} \cdot 6 \mathrm{H}_{2} \mathrm{O}, 96 \%\right)$, (3-chloropropyl) trimethoxysilane (CPTMS, 97\%) were purchased from Sigma Aldrich. (3Aminopropyl)trimethoxysilane (APTMS, 97\%), zirconium chloride $\left(\mathrm{ZrCl}_{4}, 99.5+\%\right), 4,4$ 'biphenyldicarboxylic acid (BPDC, $\mathrm{C}_{14} \mathrm{H}_{10} \mathrm{O}_{4}, 97 \%$ ), calcium chloride dihydrate $\left(\mathrm{CaCl}_{2} \cdot 2 \mathrm{H}_{2} \mathrm{O}\right.$, 99\%) and lithium chloride $(\mathrm{LiCl}, 99 \%)$ were procured from Alfa Aesar. $N, N-$ Dimethylformamide (DMF, $99 \%$ ), toluene $\left(\mathrm{C}_{7} \mathrm{H}_{8}, 99.5 \%\right)$, aqueous ammonia solution $\left(\mathrm{NH}_{3}\right.$, $25 \%)$, sodium hydroxide $(\mathrm{NaOH}, 99 \%)$, methanol $\left(\mathrm{CH}_{4} \mathrm{O}, 99.6 \%\right)$, hydrochloric acid $(\mathrm{HCl}$, $35 \%)$, sodium chloride $(\mathrm{NaCl}, 99 \%)$ and ethanol $\left(\mathrm{EtOH}, \mathrm{C}_{2} \mathrm{H}_{6} \mathrm{O}, 98 \%\right)$ were bought from OCI Co. Cotton ( $5 \mathrm{~cm} \times 5 \mathrm{~cm} \times 0.25 \mathrm{~mm})$, incense $(24 \mathrm{~cm}$, length $\times 1.5 \mathrm{~mm}$ OD) and mosquito incense (spiral type, total diameter: $106 \mathrm{~mm}$, height of coil $3.8 \mathrm{~mm}$, width of coil: $5 \mathrm{~mm}$ ) samples were purchased from local shops.

\section{Synthesis of MIL-101 and UiO-67}

MIL-101 was synthesized from $\mathrm{CrCl}_{3} \cdot 6 \mathrm{H}_{2} \mathrm{O}$, TPA and deionized water similar to a reported method. ${ }^{1}$ The reactants composition was $1.0 \mathrm{CrCl}_{3} \cdot 6 \mathrm{H}_{2} \mathrm{O}: 1.0 \mathrm{TPA}: 300 \mathrm{H}_{2} \mathrm{O}$. The precursor of $30 \mathrm{~g}$ was loaded in a Teflon-lined autoclave and put in a preheated electric oven at $210{ }^{\circ} \mathrm{C}$ for $8 \mathrm{~h}$. After the reaction, the autoclave was cooled to room temperature and solid greencolored products were recovered by filtration. After synthesis, the MOF was purified in three steps. ${ }^{1}$ In the first step, $1.0 \mathrm{~g} \mathrm{MIL-101}$ was added to $300 \mathrm{~mL}$ water and stirred magnetically for $5 \mathrm{~h}$ at $70{ }^{\circ} \mathrm{C}$. Then the MOF was filtered and dried overnight in a drying oven. In the second step, the dried MOF was added to $250 \mathrm{ml}$ ethanol; stirred magnetically at $60{ }^{\circ} \mathrm{C}$ for $3 \mathrm{~h}$ and then filtered. In the third step, the dried MOF from the second step was added to $150 \mathrm{ml} .30$ $\mathrm{mM} \mathrm{NH} \mathrm{N}_{4} \mathrm{~F}$ aq. solution and stirred for $10 \mathrm{~h}$ at $60{ }^{\circ} \mathrm{C}$. After that, it was filtered and washed at 
least five times with hot water and then dried in a drying oven again. Finally, the purified MIL101 was dehydrated at $150^{\circ} \mathrm{C}$ overnight and stored in a desiccator.

UiO-67 was synthesized to follow a reported procedure. ${ }^{2} \mathrm{ZrCl}_{4}(1.35 \mathrm{mmol}), \mathrm{DMF}(25 \mathrm{ml})$, and $\mathrm{HCl}(12 \mathrm{M}, 2.5 \mathrm{ml})$ were mixed well under sonication for $20 \mathrm{~min}$. DMF (50 ml) and BPDC (1.9 mmol) were added to the above mixture and mixed well for 20 min under sonication. The reaction mixture, transferred to a glass reactor, was reacted for $12 \mathrm{~h}$ at $80{ }^{\circ} \mathrm{C}$ under stirring. After the crystallization, the mixture was cooled down to room temperature, separated by filtration, washed with ethanol (2 times), and dried at $150{ }^{\circ} \mathrm{C}$ for $12 \mathrm{~h}$; and recovered UiO-67 was stored for next uses.

\section{Loading $\mathrm{CaCl}_{2}$ or $\mathrm{LiCl}$ onto MOFs}

Ionic salts $\left(\mathrm{CaCl}_{2}\right.$ or $\left.\mathrm{LiCl}\right)$ were loaded onto MOFs, to follow reported methods. ${ }^{3,4}$ $\mathrm{CaCl}_{2} @ \mathrm{MOF}$ was prepared by impregnation method. $0.1 \mathrm{~g}$ of MOF was dispersed into $10 \mathrm{ml}$ of $\mathrm{H}_{2} \mathrm{O}$ with the different weight ratio of $\mathrm{CaCl}_{2}$ based on weight of $\mathrm{MOF}$ from $10 \mathrm{wt} \%$ to $40 \mathrm{wt} \%$. The suspension was stirred for $6 \mathrm{~h}$ at room temperature. The $\mathrm{CaCl}_{2} @ \mathrm{MOF}$ was obtained by rotary evaporator and dried at $100{ }^{\circ} \mathrm{C}$ overnight for further experiment. ${ }^{3}$ LiCl@MOF was similarly prepared by the impregnation method. $0.1 \mathrm{~g}$ of MOF was dispersed into $10 \mathrm{ml}$ methanol solution with the different weight ratio of $\mathrm{LiCl}$ based on weight of MOF from $10 \mathrm{wt} \%$ to $40 \mathrm{wt} \%$. The suspension was stirred for $6 \mathrm{~h}$ at room temperature. The LiCl@MOF was obtained by rotary evaporator and dried at $100{ }^{\circ} \mathrm{C}$ overnight for further experiment. ${ }^{4}$ Obtained ISs@MOFs were named IS $(x) @$ MOF, where $x$ means the wt $\%$ of IS, based on total weight of MOF. 


\section{MOFs coating onto substrates}

Cotton fabrics (each, $\left.5 \times 5 \mathrm{~cm}^{2}\right)$ were pre-treated by wetting in an $\mathrm{NaOH}$ aq. solution $(0.5$ $\mathrm{M}, 200 \mathrm{ml}$ ) for $2 \mathrm{~h}$. After the pre-treatment, the obtained cotton pieces were removed from the solution, and washed with water to remove any impurities, and finally dried with a conventional oven for $12 \mathrm{~h}$ at $70{ }^{\circ} \mathrm{C}$.

Prepared MOFs (such as MIL-101, ISs@MIL-101s, UiO-67 and ISs@UiO-67s) were coated on the cotton via formation of a covalent bond between a MOF crystal and the pretreated cotton, similar to a reported procedure. ${ }^{5}$ However, a coordination bond between $-\mathrm{NH}_{2}$ (of silane) and open metal site of MOF was utilized for the case of MIL-101.6 Dried cotton specimen was put into a solution containing $0.01 \mathrm{mmol}$ of (3-aminopropyl)trimethoxysilane (APTMS) [or (3-chloropropyl) trimethoxysilane (CPTMS) for UiO-67] and toluene (200 ml). The cotton/MOF-containing solution was heated at $100{ }^{\circ} \mathrm{C}$ for $2 \mathrm{~h}$ in order to introduce APTMS/CPTMS into the cotton via a reaction between -OH group of cotton and methoxy group of APTMS/CPTMS. After maintaining for $2 \mathrm{~h}$, the reactor (containing APTMS/CPTMSloaded cotton) was cooled down to room temperature, and a prepared/well-dried MOF (0.2 g) was added to the reactor, and further heated and maintained at $80^{\circ} \mathrm{C}$ for $48 \mathrm{~h}$ under magnetic stirring to coat the MOF on cotton. Then, the reactor (containing cotton coated with a MOF) was cooled down to room temperature. The cotton coated with a MOF was recovered by filtration, washed with ethanol several times, and dried in a conventional oven at $100{ }^{\circ} \mathrm{C}$ for 12 h.

\section{Characterization}

Powder X-ray diffraction patterns of MOFs and substrates (with or without MOFs coating) 
were obtained with a diffractometer (D2 Phaser, Bruker, $\mathrm{Cu}$ K $\alpha$ radiation). Nitrogen adsorption isotherms of MOFs were acquired at $77 \mathrm{~K}$ using a surface and porosity analyzer (Tristar II 3020, Micromeritics). Before measurements, the samples were evacuated for $12 \mathrm{~h}$ at $150{ }^{\circ} \mathrm{C}$. Surface area and micropore volume of MOFs were calculated by using the Brunauer-Emmett-Teller (BET) equation and t-plot. Total pore volumes were calculated by using the quantities of adsorbed $\mathrm{N}_{2}$ under $\mathrm{P} / \mathrm{P}_{0}=0.99$. The morphology of the materials was checked by a scanning electron microscope (SEM, Hitachi SU-8220). The chemical bonds of the captured particulate matters were identified by using a Fourier-transform infrared spectrometer (FTIR, Jasco FTIR4100) fitted with an attenuated total reflectance module (maximum resolution: $4.0 \mathrm{~cm}^{-1}$ ). Thermogravimetric analysis (TGA) of $\mathrm{CaCl}_{2} @$ MIL-101s were done with Auto TGA-DSC (Discovery SDT 650, TA instruments) under the nitrogen flow. Before the TGA analysis, samples were fully hydrated by putting them over saturated $\mathrm{NaCl}$ aq. solution with a desiccator.

\section{Evaluation of PM removal}

PM removal experiments, including checking the removal efficiency and pressure drop with various filters, were carried out with a homemade measurement system. ${ }^{2}$ The device was composed of two chambers (divided by an acryl plate with or without a hole). PMs were generated inside of the left chamber by burning of incenses. After the PM concentration was stabilized to an intended level, a filter was rapidly set on the middle of the chambers, and the PM-containing air was flown continuously to the right chamber by air feeding. Thus, air (contaminated with PMs in constant concentration) was supplied from the left chamber to the right chamber with a face velocity of $0.2 \mathrm{~m} \mathrm{~s}^{-1}$ (flow rate of air: $11 \mathrm{~L} / \mathrm{min}$, and window size of 
filter for airflow: $3 \times 3 \mathrm{~cm}^{2}$ ). Concentrations of PM2.5 and PM10, in both the left and right chambers, were measured with independent commercial PM meters (CEM, DT-9681). The removal efficiency of PM (or the degree of reduction in PM concentrations after passing through the filter) was calculated by comparing the PM concentrations in the two chambers. The pressure drop was measured with a differential pressure gauge (ULFA Tech Corporation, PDT series), during the air flow or PM capture. Scheme S1 shows the schematic diagram of the equipment to evaluate the performances of filters in removing PM from air.

PM removal experiments were done three times and the average values (rel. error less than 5\%) were reported in this work. Unless otherwise specified, the initial PM concentrations were: PM2.5: $310( \pm 5) \mu \mathrm{g} / \mathrm{m}^{3}$; PM10: $710( \pm 10) \mu \mathrm{g} / \mathrm{m}^{3}$. 


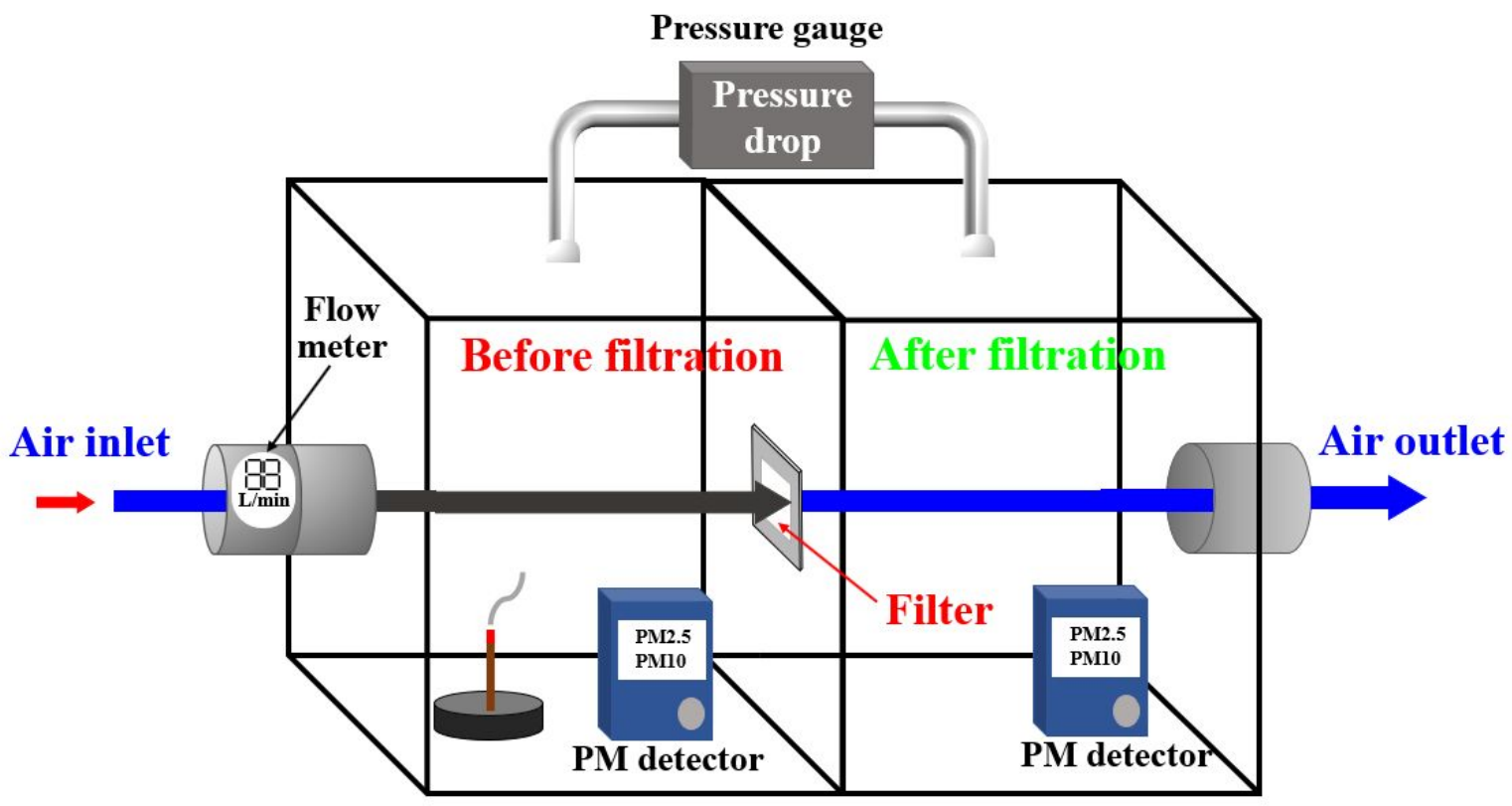

Scheme S1. Schematic diagram of an equipment to evaluate the performances of filters in the removal of PM from air. The size of one chamber is $40 \times 60 \times 60 \mathrm{~cm}^{3}$. 
Table S1. Performances of bare cotton and $\mathrm{CaCl}_{2} @ \mathrm{UiO}-67 \mathrm{~s} /$ cotton filters in the removal of PMs from air. BET surface areas and coated quantities of UiO-67s are also shown.

\begin{tabular}{|c|c|c|c|c|c|c|c|}
\hline Filter & $\begin{array}{l}\mathrm{SA}_{\mathrm{BET}} \\
\left(\mathrm{m}^{2} \cdot \mathrm{g}^{-1}\right) \\
\text { of } \mathrm{MOF}\end{array}$ & $\begin{array}{c}\text { Quantity } \\
\text { of loaded } \\
\text { MOFs on } \\
\text { cotton } \\
(\mathrm{mg} / \mathrm{g})\end{array}$ & $\begin{array}{l}\text { Pressure } \\
\text { drop }(\mathrm{Pa})^{\mathrm{a}}\end{array}$ & $\begin{array}{l}\text { Removal } \\
\text { of PM2.5 } \\
(\%)^{\mathrm{a}}\end{array}$ & $\begin{array}{c}\mathrm{QF}^{*}\left(\mathrm{~Pa}^{-1}\right. \\
\mathrm{PM} 2.5)^{\mathrm{a}}\end{array}$ & $\begin{array}{l}\text { Removal } \\
\text { of PM10 } \\
(\%)^{\mathrm{a}}\end{array}$ & $\begin{array}{l}\mathrm{QF}\left(\mathrm{Pa}^{-1},\right. \\
\mathrm{PM} 10)^{\mathrm{a}}\end{array}$ \\
\hline Cotton & - & 0 & 28 & 35.2 & 0.016 & 47.7 & 0.023 \\
\hline UiO-67/cotton & 2,399 & 198.1 & 32 & 72.7 & 0.043 & 77.3 & 0.049 \\
\hline $\begin{array}{l}\mathrm{CaCl}_{2}(10) @ \text { UiO- } \\
67 / \text { cotton }\end{array}$ & 1,745 & 196.6 & 33 & 84.3 & 0.056 & 87.6 & 0.063 \\
\hline $\begin{array}{l}\mathrm{CaCl}_{2}(20) @ \text { UiO- } \\
67 / \text { cotton }\end{array}$ & 1,296 & 186.3 & 32 & 87.9 & 0.066 & 90.0 & 0.072 \\
\hline $\begin{array}{l}\mathrm{CaCl}_{2}(30) @ \text { UiO- } \\
67 / \text { cotton }\end{array}$ & 992 & 193.7 & 33 & 83.1 & 0.054 & 85.9 & 0.059 \\
\hline $\begin{array}{l}\mathrm{CaCl}_{2}(40) @ \text { UiO- } \\
67 / \text { cotton }\end{array}$ & 701 & 190.4 & 32 & 78.3 & 0.048 & 81.2 & 0.052 \\
\hline${ }^{*} \mathrm{QF}$ : quality facto & & & & & & & \\
\hline
\end{tabular}


Table S2. Performances of bare cotton and LiCl@UiO-67s/cotton filters in the removal of PMs from air. BET surface areas and coated quantities of UiO-67s are also shown.

\begin{tabular}{|c|c|c|c|c|c|c|c|}
\hline Filter & $\begin{array}{l}\mathrm{SA}_{\mathrm{BET}} \\
\left(\mathrm{m}^{2} \cdot \mathrm{g}^{-1}\right) \\
\text { of MOF }\end{array}$ & $\begin{array}{l}\text { Quantity } \\
\text { of loaded } \\
\text { MOFs on } \\
\text { cotton } \\
(\mathrm{mg} / \mathrm{g})\end{array}$ & $\begin{array}{l}\text { Pressure } \\
\text { drop }(\mathrm{Pa})^{\mathrm{a}}\end{array}$ & $\begin{array}{c}\text { Removal } \\
\text { of PM2.5 } \\
(\%)^{\mathrm{a}}\end{array}$ & $\begin{array}{c}\mathrm{QF}^{*}\left(\mathrm{~Pa}^{-1},\right. \\
\mathrm{PM} 2.5)^{\mathrm{a}}\end{array}$ & $\begin{array}{c}\text { Removal } \\
\text { of PM10 } \\
(\%)^{\mathrm{a}}\end{array}$ & $\begin{array}{l}\mathrm{QF}\left(\mathrm{Pa}^{-1},\right. \\
\mathrm{PM} 10)^{\mathrm{a}}\end{array}$ \\
\hline Cotton & - & 0 & 28 & 35.2 & 0.016 & 47.7 & 0.023 \\
\hline UiO-67/cotton & 2,399 & 198.1 & 32 & 72.7 & 0.043 & 77.3 & 0.049 \\
\hline $\begin{array}{l}\text { LiCl(10)@UiO- } \\
67 / \text { cotton }\end{array}$ & 1,761 & 179.1 & 31 & 77.0 & 0.047 & 81.4 & 0.054 \\
\hline $\begin{array}{l}\text { LiCl(20)@UiO- } \\
\text { 67/cotton }\end{array}$ & 1,370 & 188.8 & 32 & 84.3 & 0.058 & 87.3 & 0.064 \\
\hline $\begin{array}{l}\text { LiCl(30)@UiO- } \\
\text { 67/cotton }\end{array}$ & 1,081 & 200.3 & 32 & 75.1 & 0.043 & 80.2 & 0.051 \\
\hline $\begin{array}{l}\text { LiCl(40)@UiO- } \\
\text { 67/cotton }\end{array}$ & 757 & 199.5 & 32 & 70.3 & 0.038 & 73.7 & 0.042 \\
\hline *QF: quality fact & & & & & & & \\
\hline
\end{tabular}



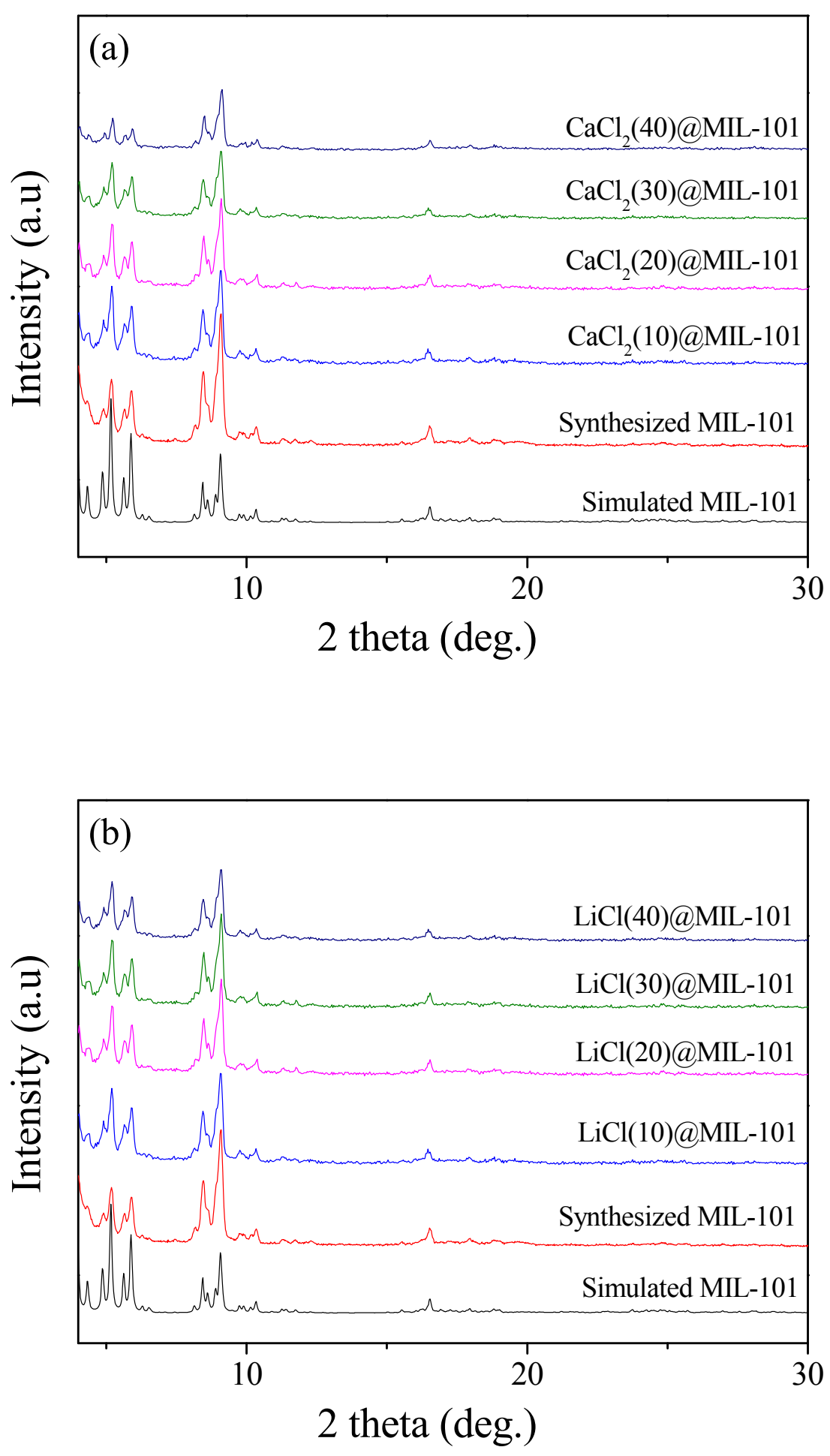

Figure S1. XRD patterns of MIL-101s, after loading (a) $\mathrm{CaCl}_{2}$ and (b) $\mathrm{LiCl}$. Calculated pattern of MIL-101 is also shown for reference. 

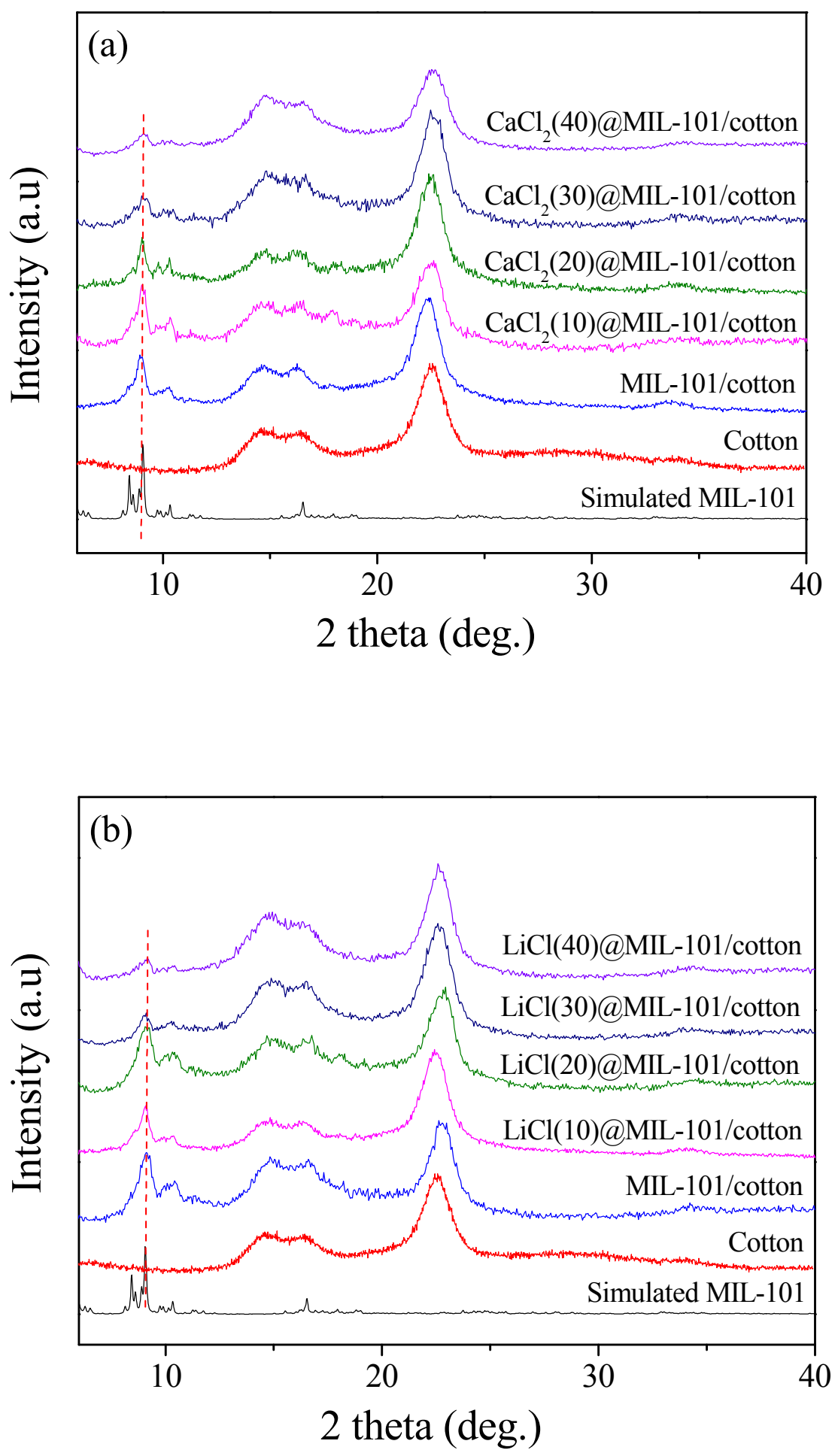

Figure S2. XRD patterns of cotton and MIL-101s/cotton, after loading (a) $\mathrm{CaCl}_{2}$ and (b) $\mathrm{LiCl}$. Calculated pattern of MIL-101 is also shown for reference. 

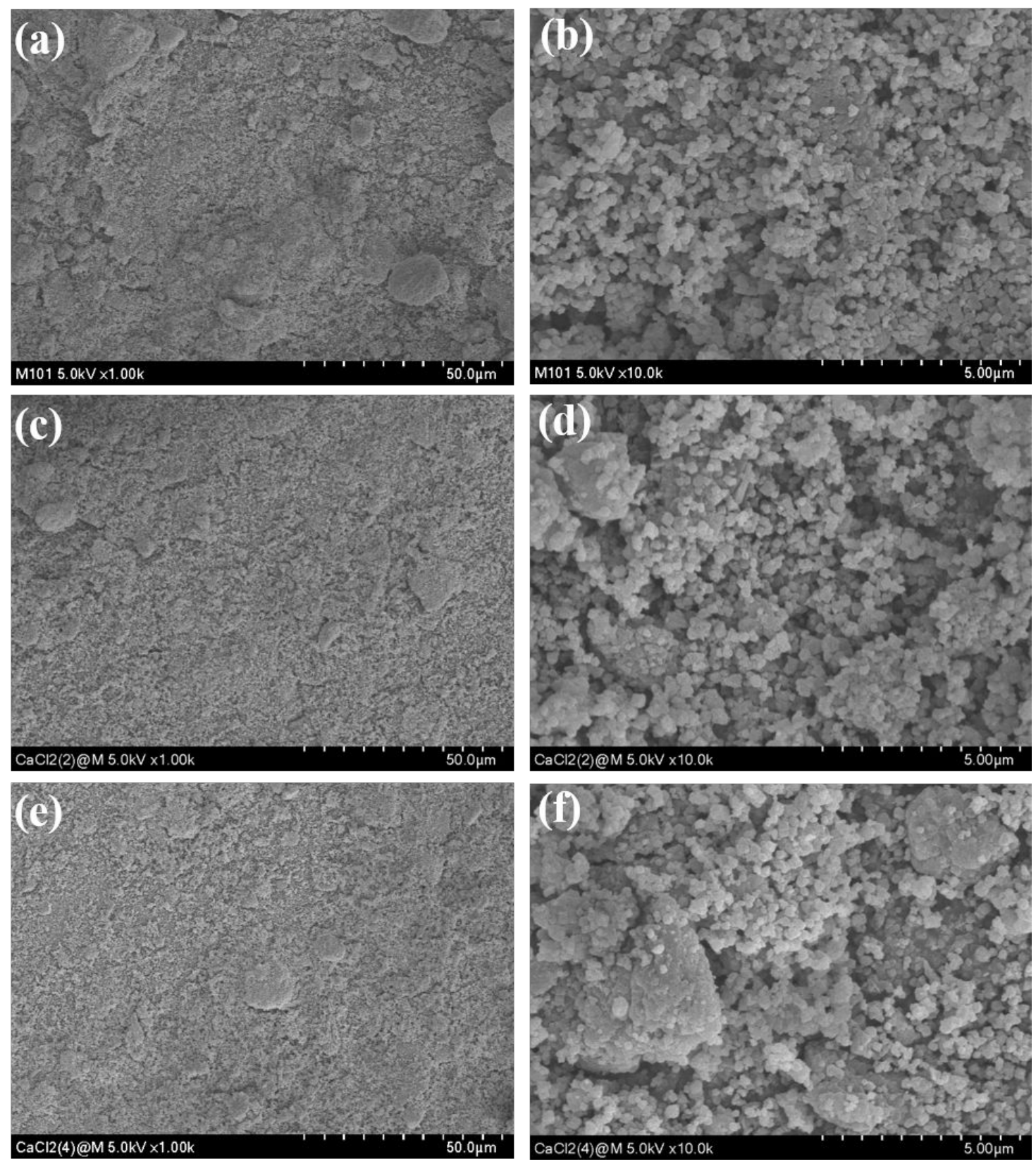

Figure S3. SEM images of (a, b) MIL-101, (c, d) $\mathrm{CaCl}_{2}(20) @ M I L-101$ and (e, f)

$\mathrm{CaCl}_{2}(40) @ \mathrm{MIL}-101 \mathrm{~s}$. The magnifications for (a, c, e) and (b, d, f) are 1,000 and 10,000, respectively. 

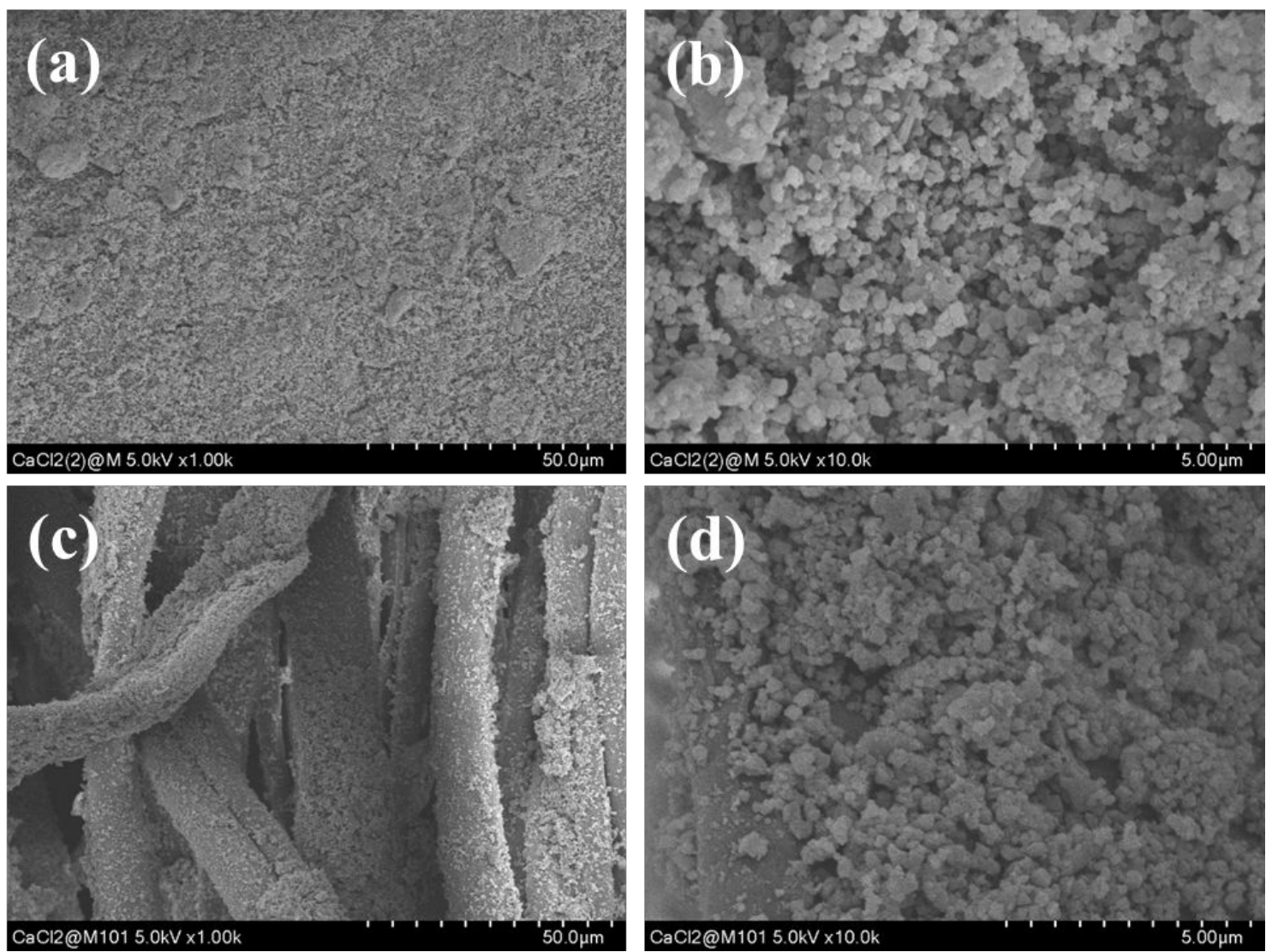

Figure S4. SEM images of (a, b) $\mathrm{CaCl}_{2}(20) @ \mathrm{MIL}-101$ and (c, d) $\mathrm{CaCl}_{2}(20) @ \mathrm{MIL}-$ 101/cotton. The magnifications for (a, c) and (b, d) are 1,000 and 10,000, respectively. 

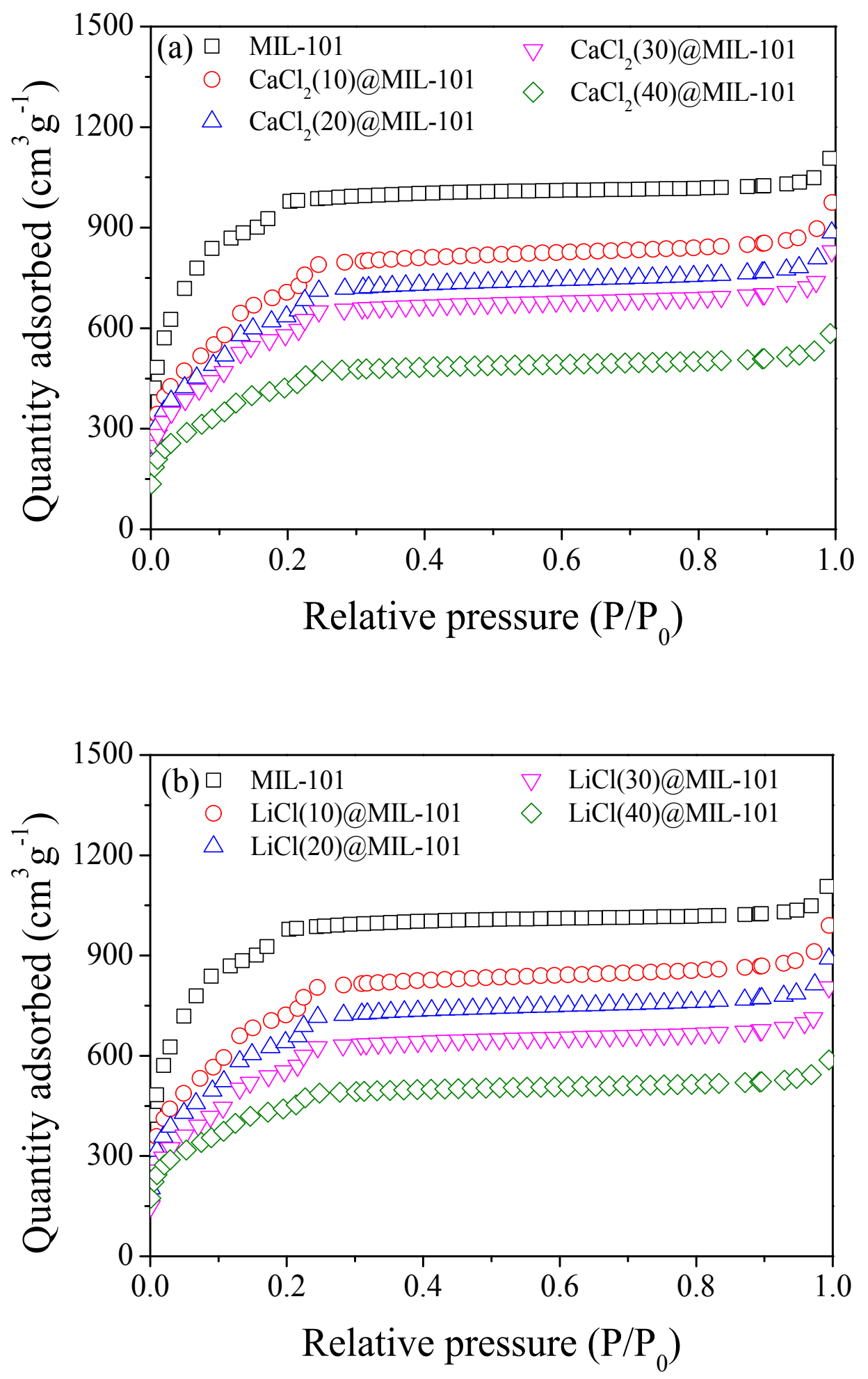

Figure S5. $\mathrm{N}_{2}$ adsorption isotherms of MIL-101s, after loading (a) $\mathrm{CaCl}_{2}$ and (b) $\mathrm{LiCl}$. 

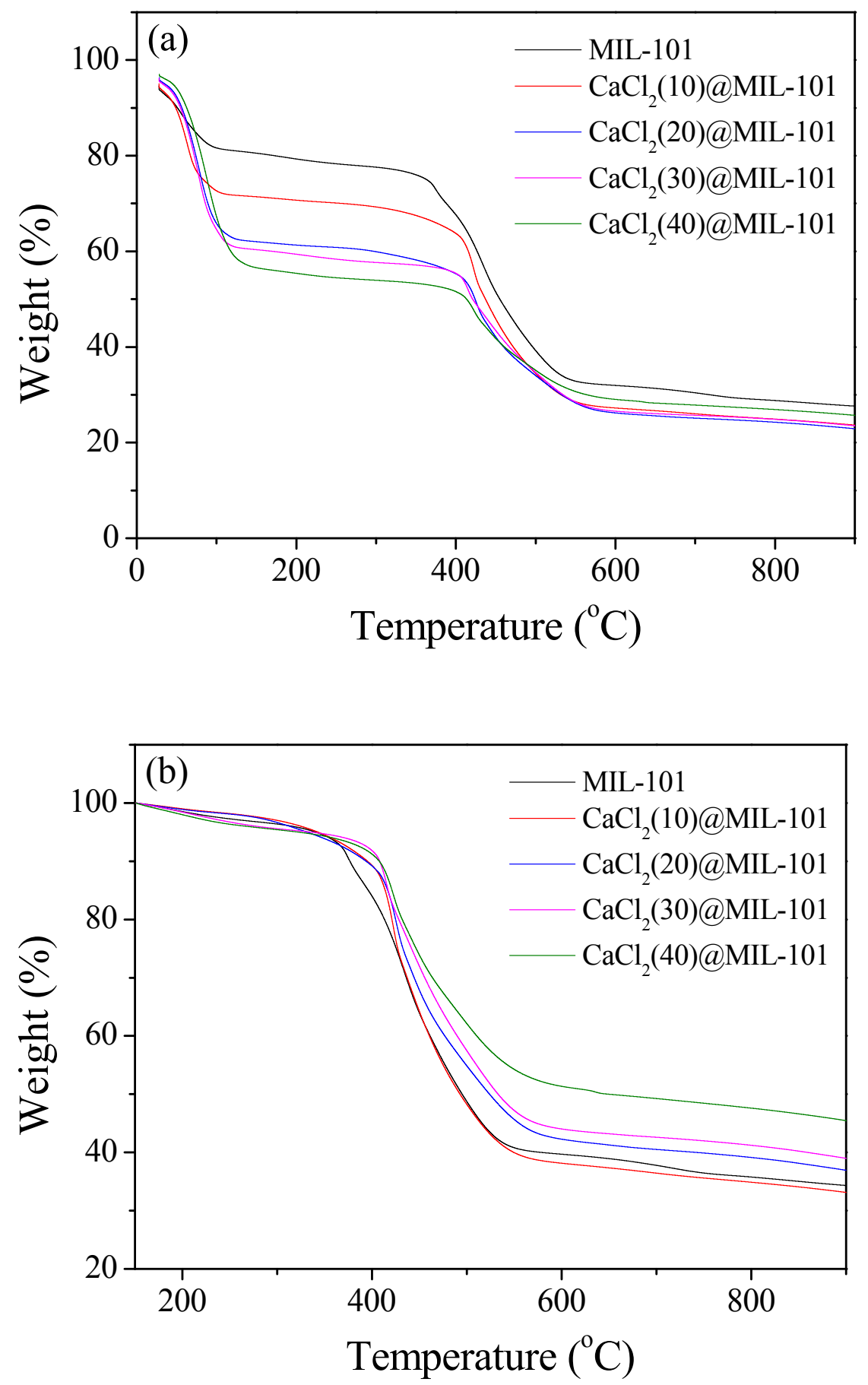

Figure S6. TGA patterns of MIL-101 and $\mathrm{CaCl}_{2} @$ MIL-101s. Patterns in (a) show the results of fully hydrated samples; and the TGA results in (b) present the change of sample weight, based on the sample treated at $150^{\circ} \mathrm{C}$. 

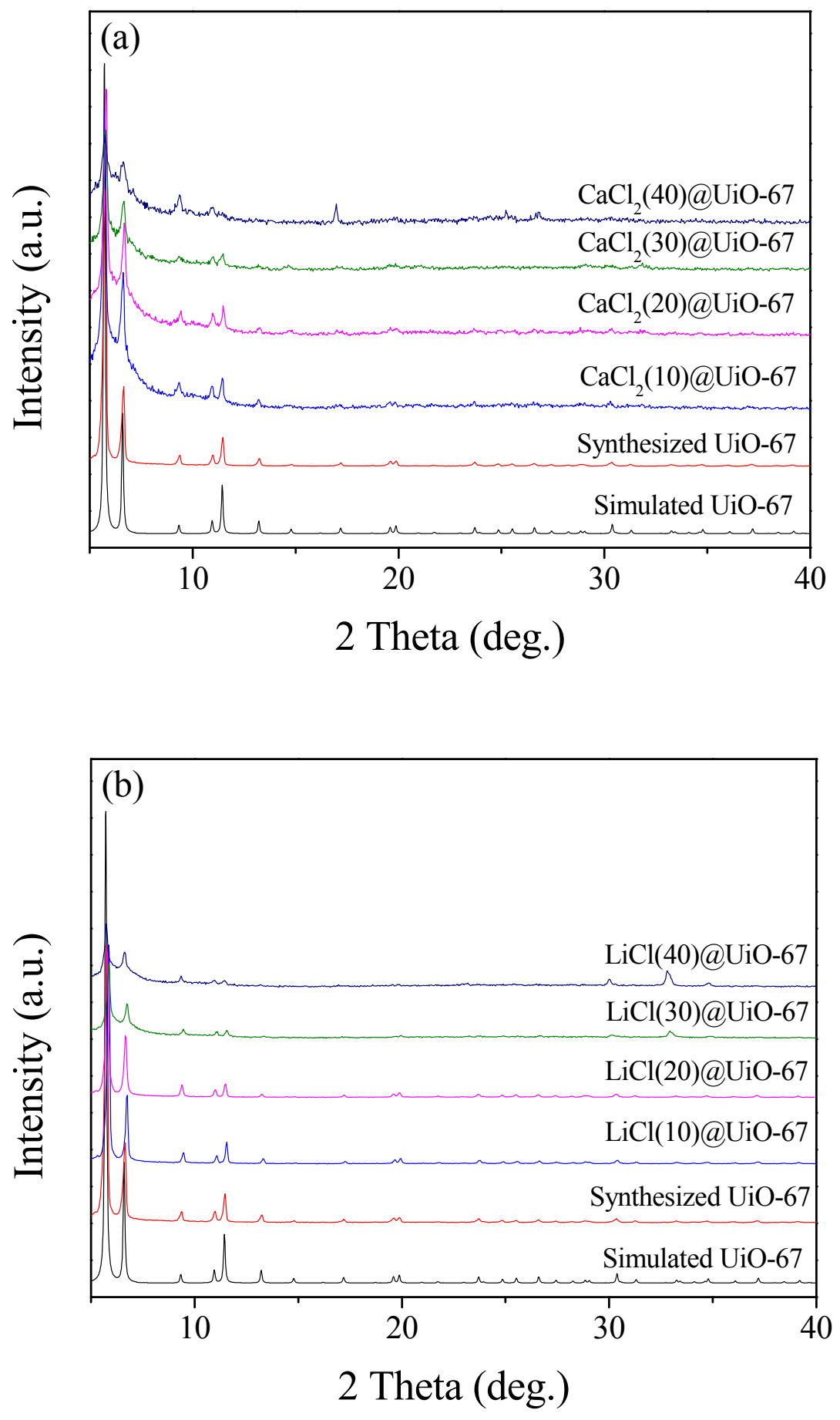

Figure S7. XRD patterns of UiO-67s, after loading (a) $\mathrm{CaCl}_{2}$ and (b) $\mathrm{LiCl}$. Calculated pattern of UiO-67 is also shown for reference. 

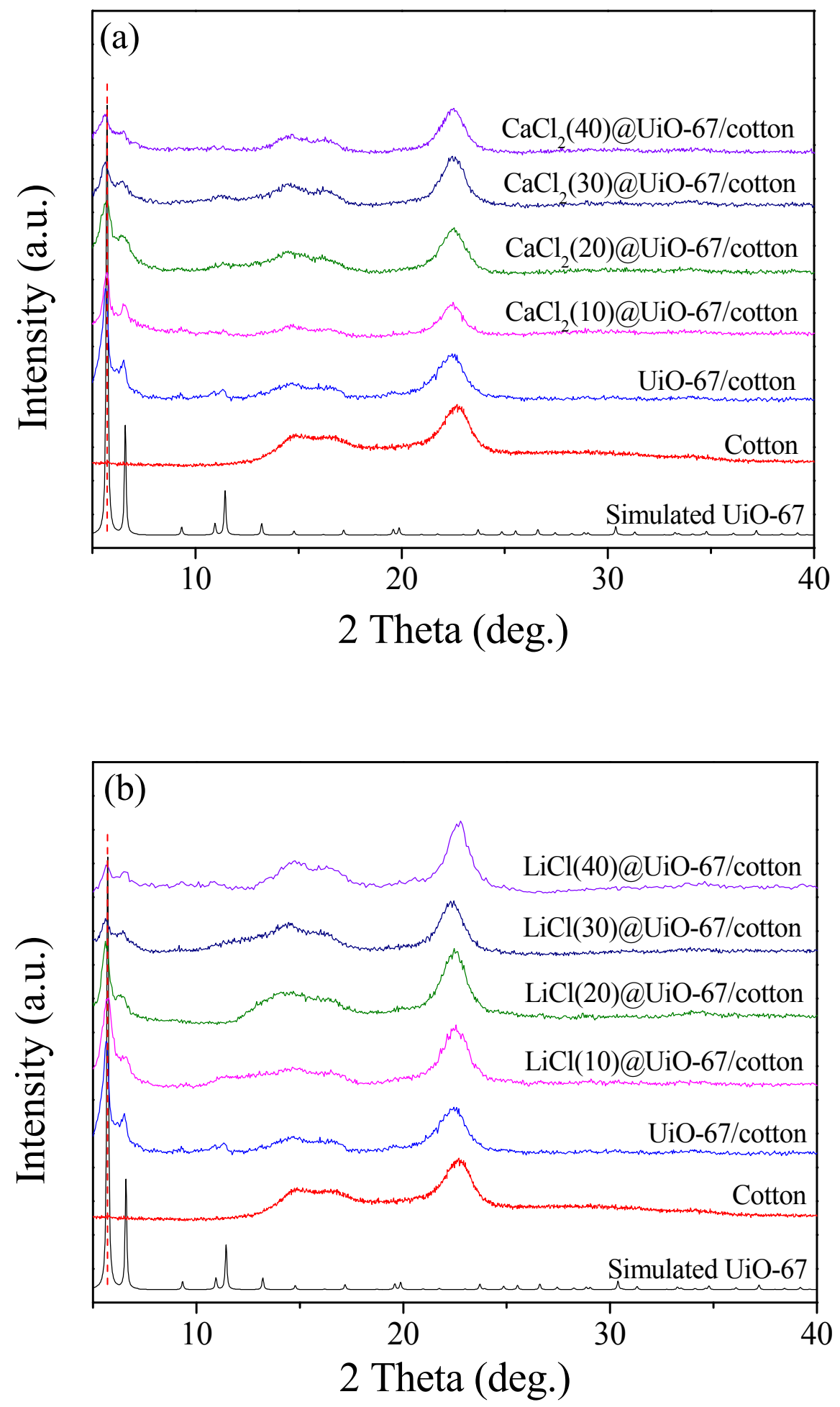

Figure S8. XRD patterns of cotton and UiO-67s/cotton, after loading (a) $\mathrm{CaCl}_{2}$ and (b) $\mathrm{LiCl}$. Calculated pattern of UiO-67 is also shown for reference. 

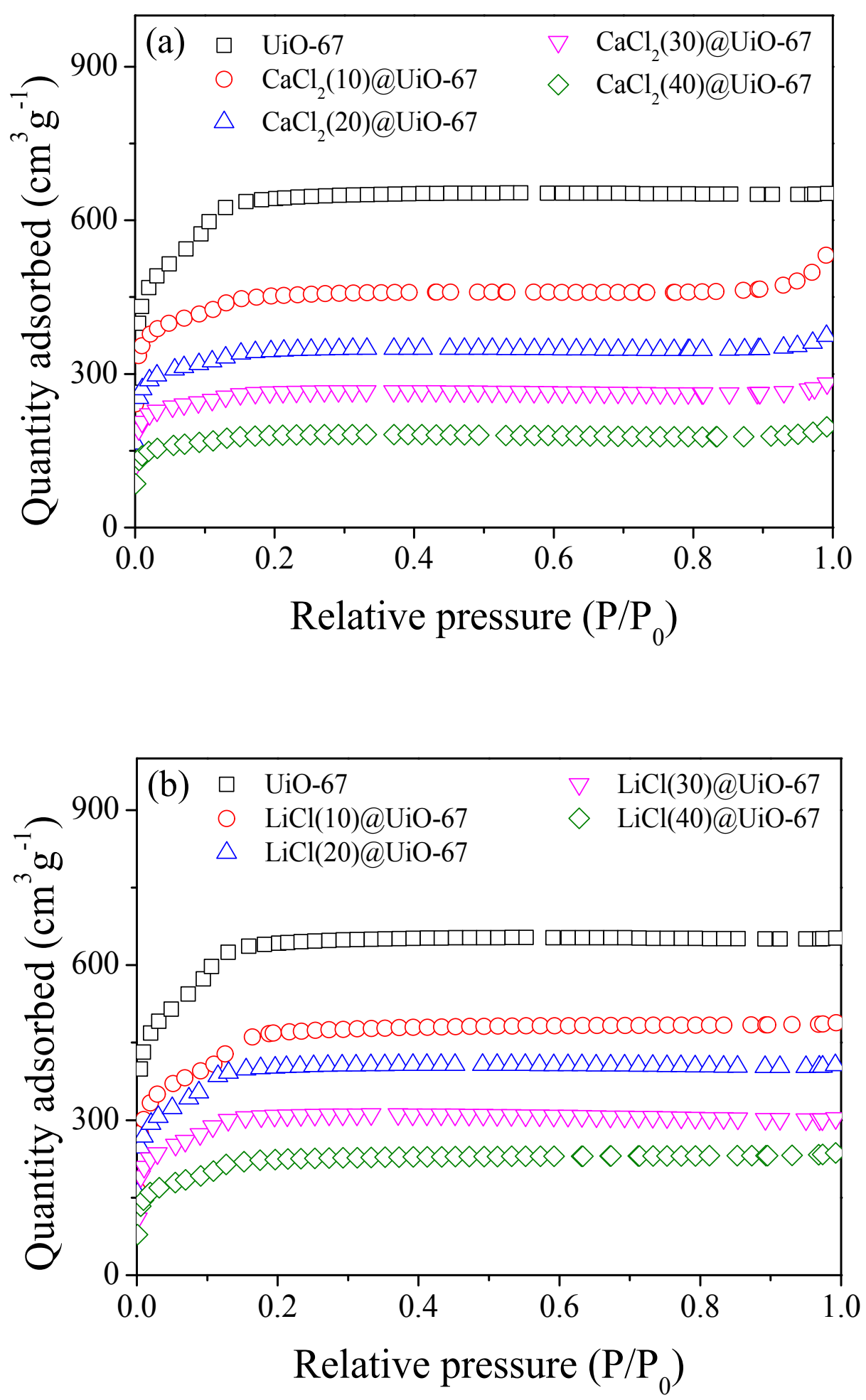

Figure S9. $\mathrm{N}_{2}$ adsorption isotherms of UiO-67s, after loading (a) $\mathrm{CaCl}_{2}$ and (b) $\mathrm{LiCl}$. 

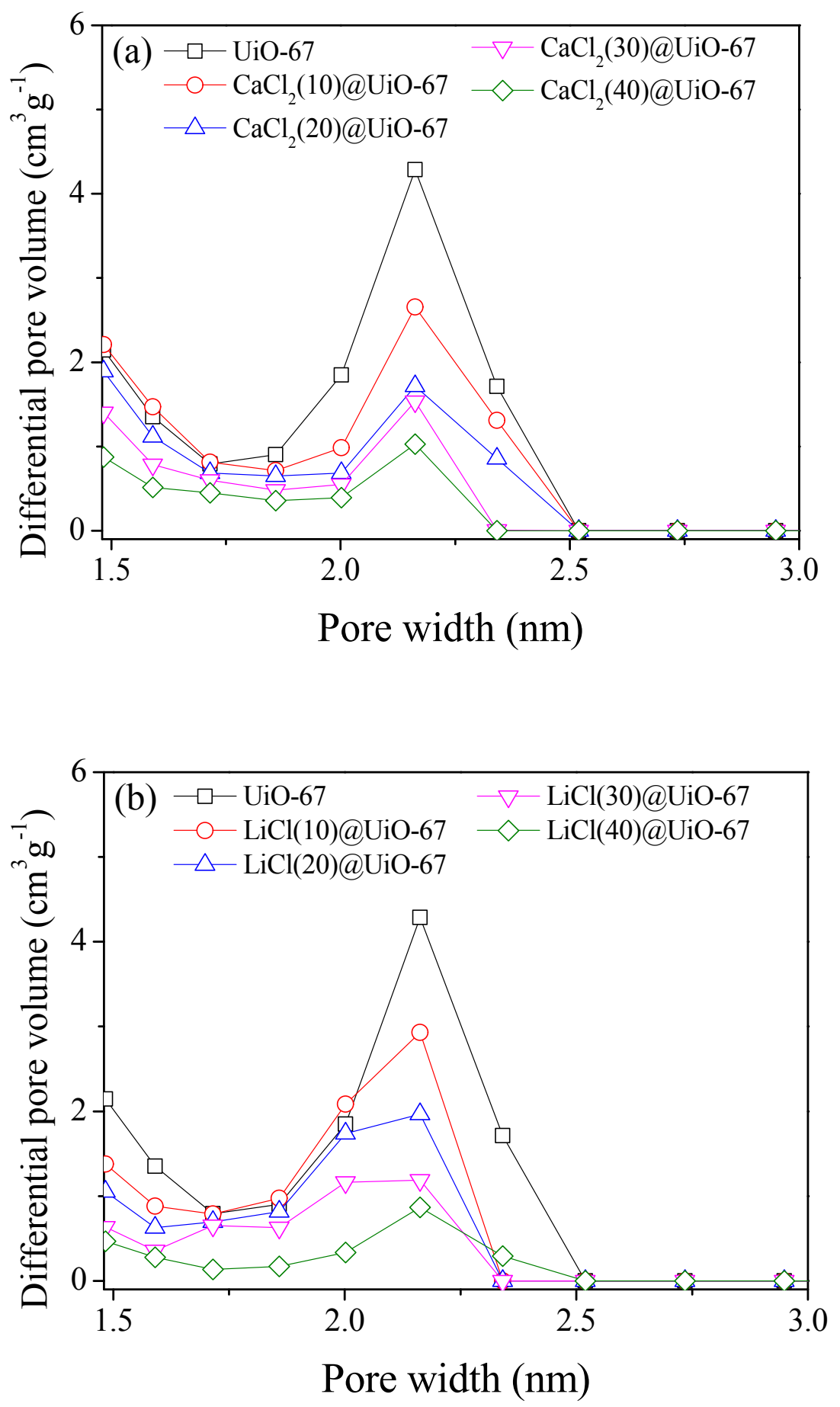

Figure S10. Pore size distributions (PSDs) of (a) $\mathrm{CaCl}_{2} @ \mathrm{UiO}-67 \mathrm{~s}$ and (b) $\mathrm{LiCl} @ \mathrm{UiO}-67 \mathrm{~s}$, obtained from the $\mathrm{N}_{2}$ isotherms (desorption branch) by non-local density functional theory (NLDFT). 

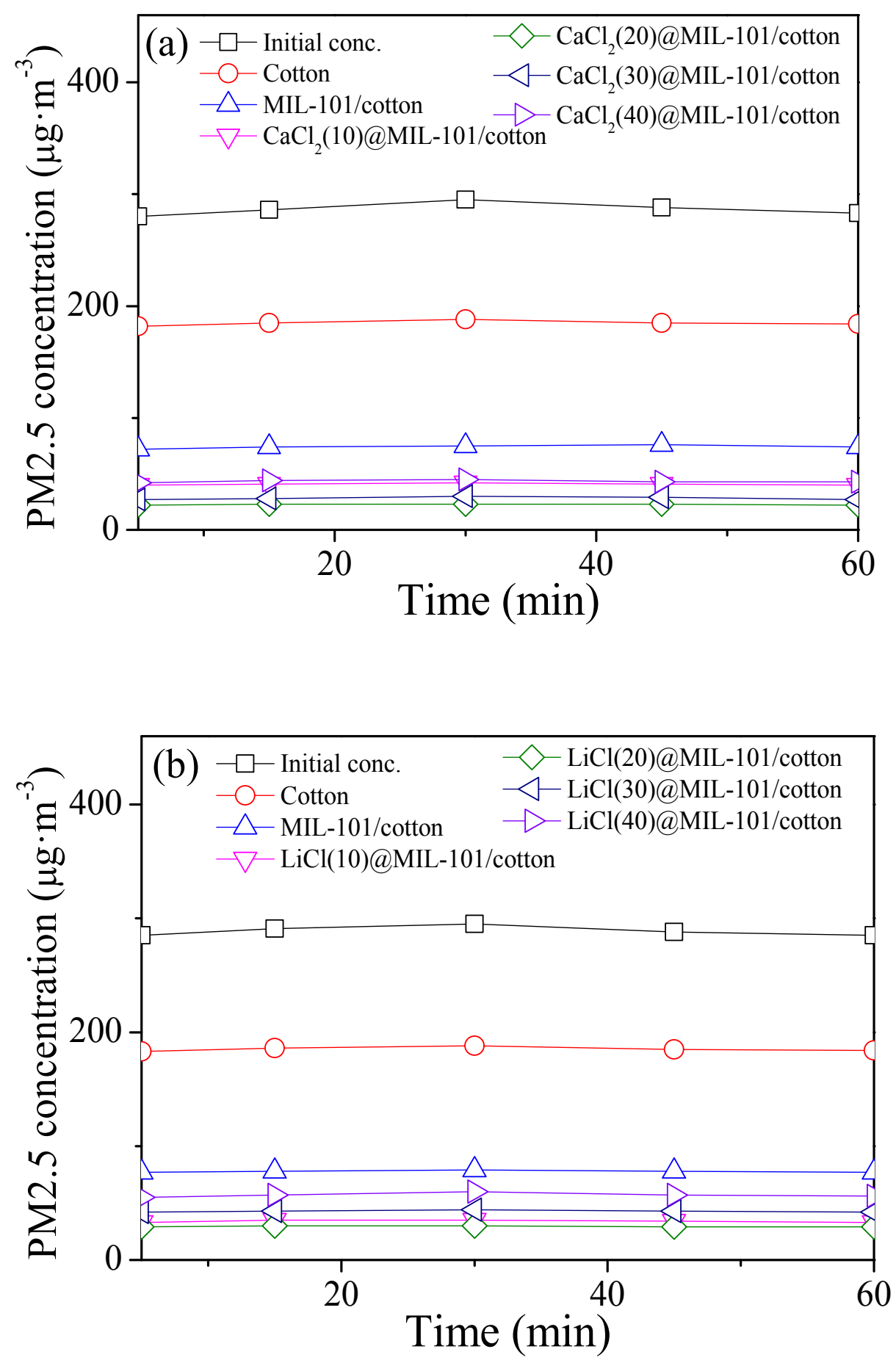

Figure S11. PM2.5 concentrations before and after passing through (for 0-60 $\mathrm{min}$ ) cotton, MIL-101/cotton, (a) CaCl $@$ @MIL-101s/cotton and (b) LiCl@MIL-101s/cotton. 

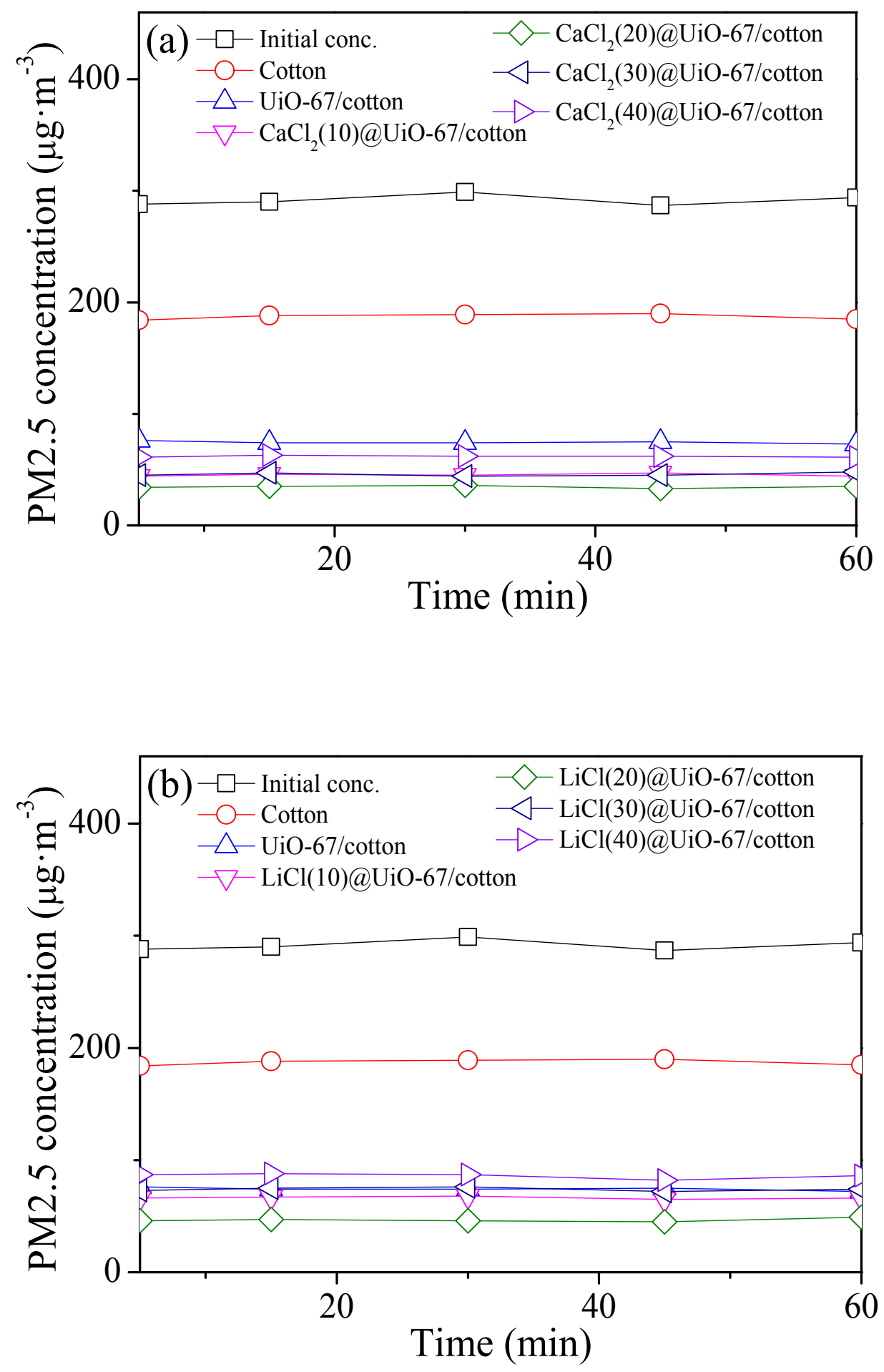

Figure S12. PM2.5 concentrations before and after passing through (for 0-60 min) cotton, UiO-67/cotton, (a) $\mathrm{CaCl}_{2} @$ UiO-67s/cotton and (b) LiCl@UiO-67s/cotton. 

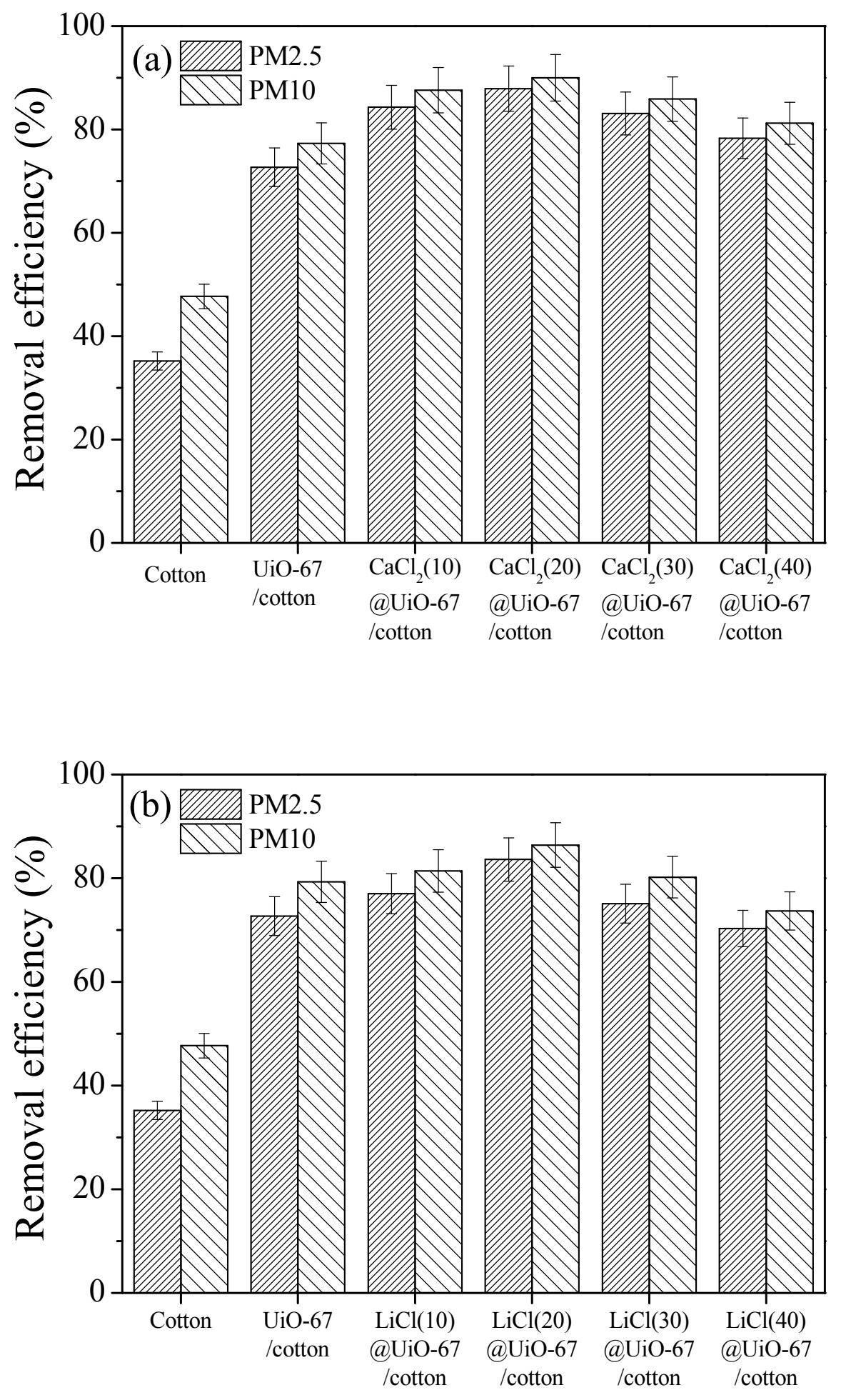

Figure S13. Removal efficiencies (for PM2.5 and PM10) of (a) $\mathrm{CaCl}_{2} @ \mathrm{UiO}-67 \mathrm{~s} /$ cotton and (b) LiCl@UiO-67s/cotton after filtration for $60 \mathrm{~min}$. 

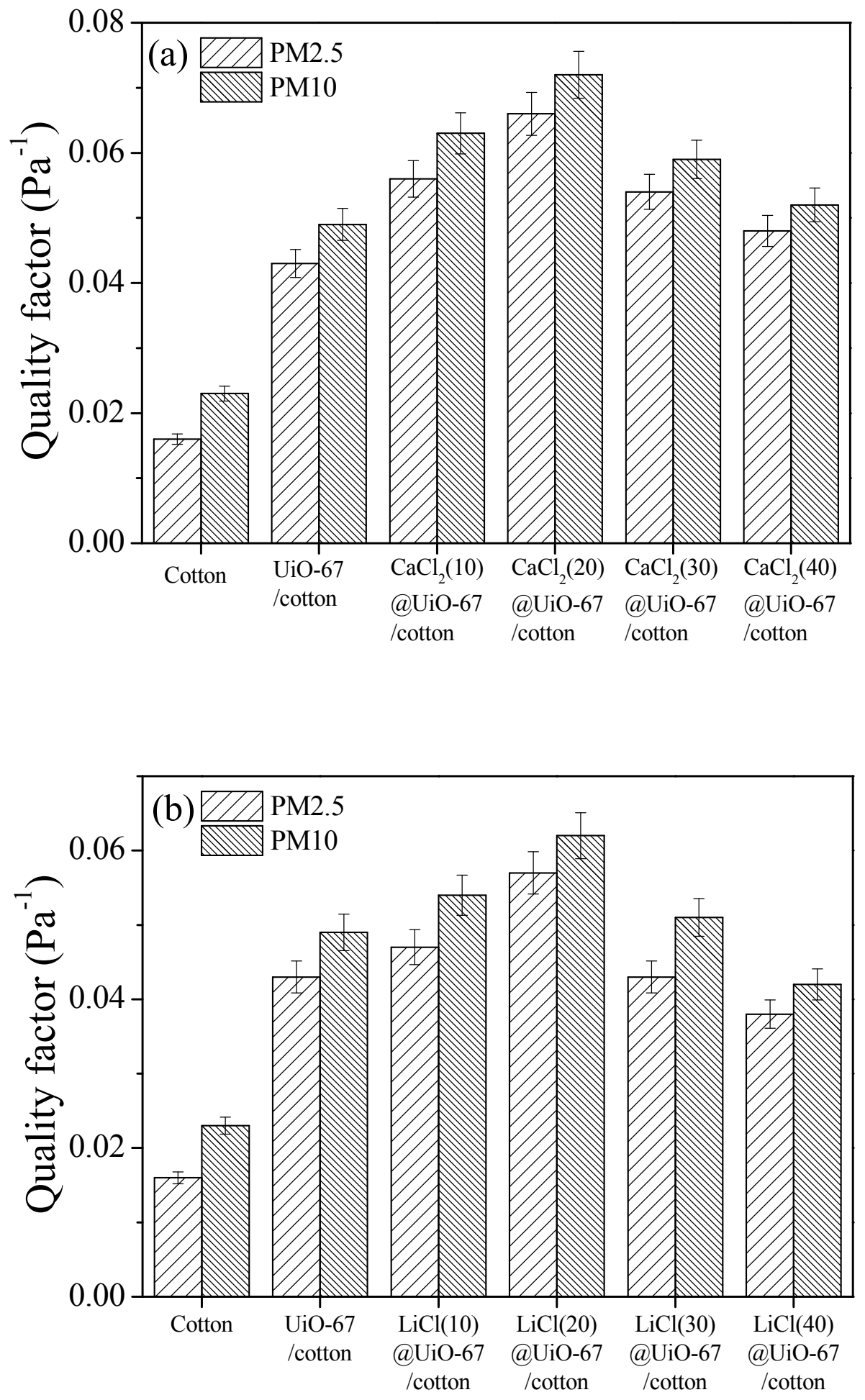

Figure S14. Quality factors (for PM2.5 and PM10) of (a) $\mathrm{CaCl}_{2} @ \mathrm{UiO}-67 \mathrm{~s} /$ cotton and (b) LiCl@UiO-67s/cotton after filtration for 60 min. 


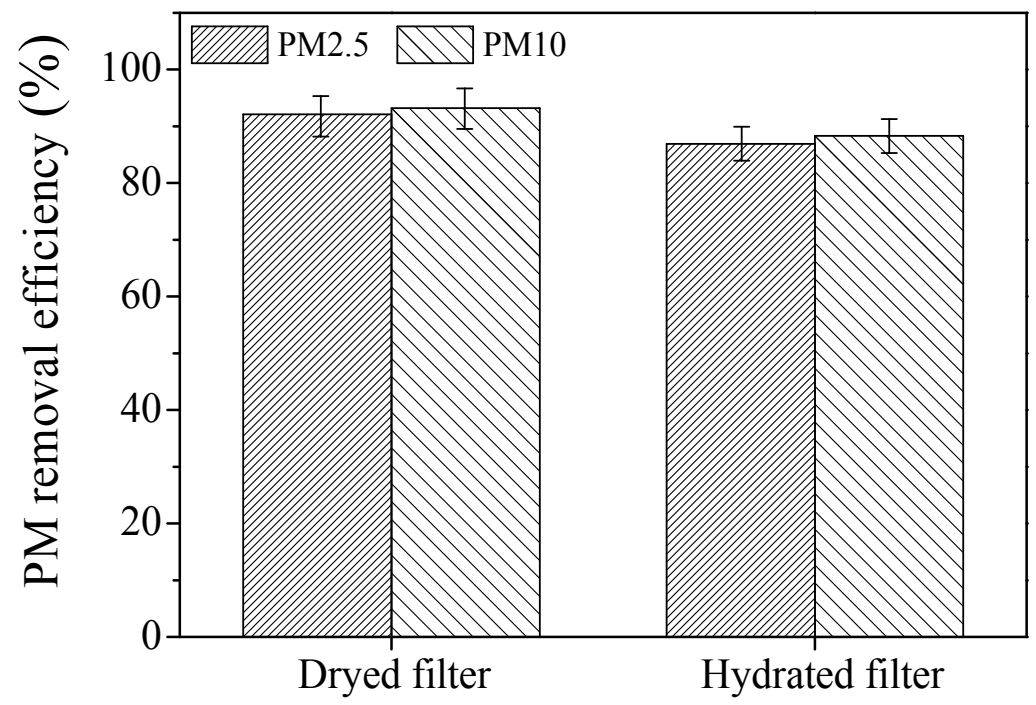

Figure S15. Effect of hydration of $\mathrm{CaCl}_{2}(20) @ \mathrm{MIL}-101 /$ cotton on the removal efficiencies (for PM2.5 and PM10). 

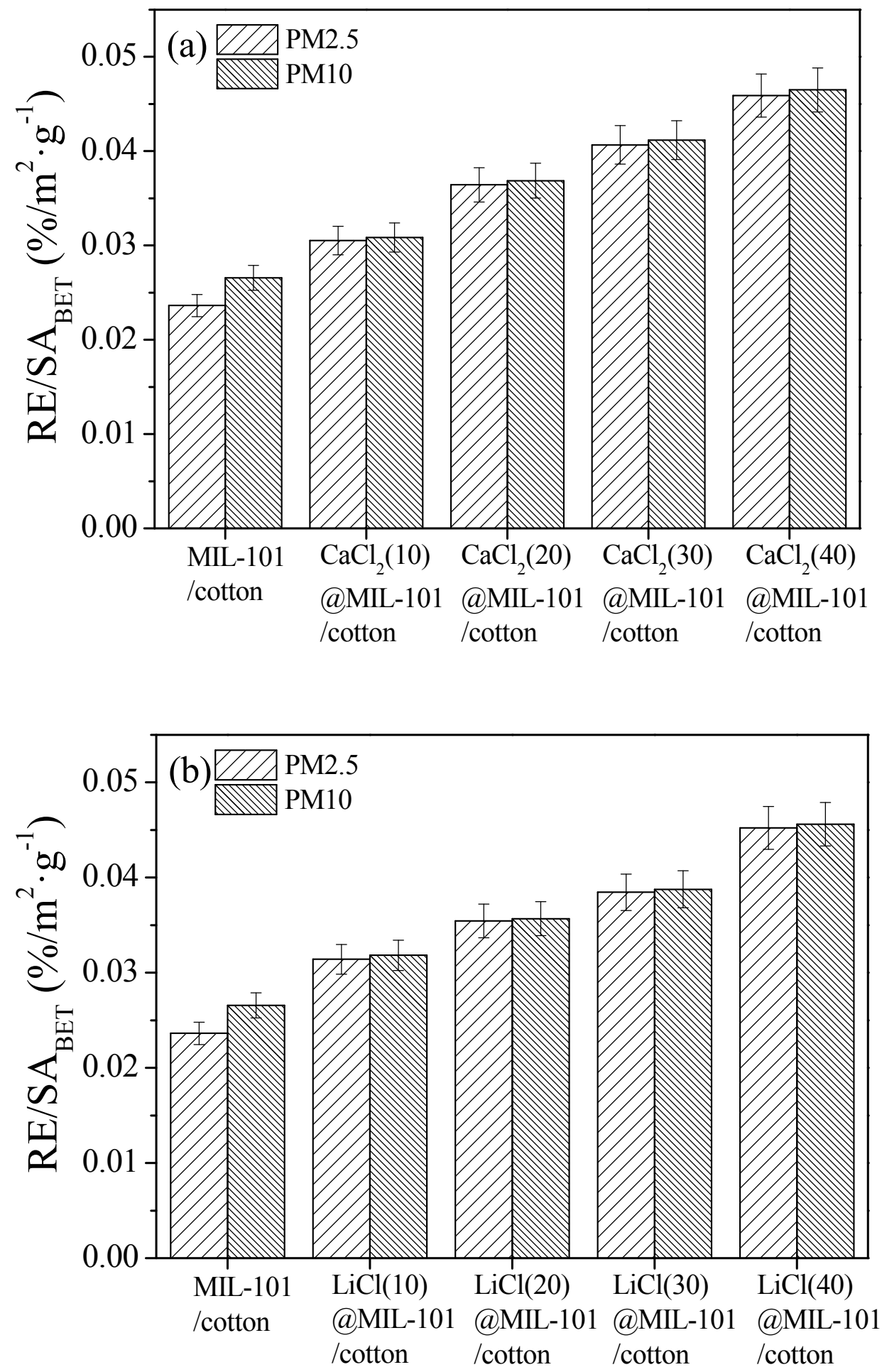

Figure S16. Removal efficiencies (for PM2.5 and PM10) of (a) $\mathrm{CaCl}_{2} @ \mathrm{MIL}-101 \mathrm{~s} /$ cotton and (b) LiCl@MIL-101s/cotton, based on unit surface area of MIL-101s, after filtration for $60 \mathrm{~min}$. 

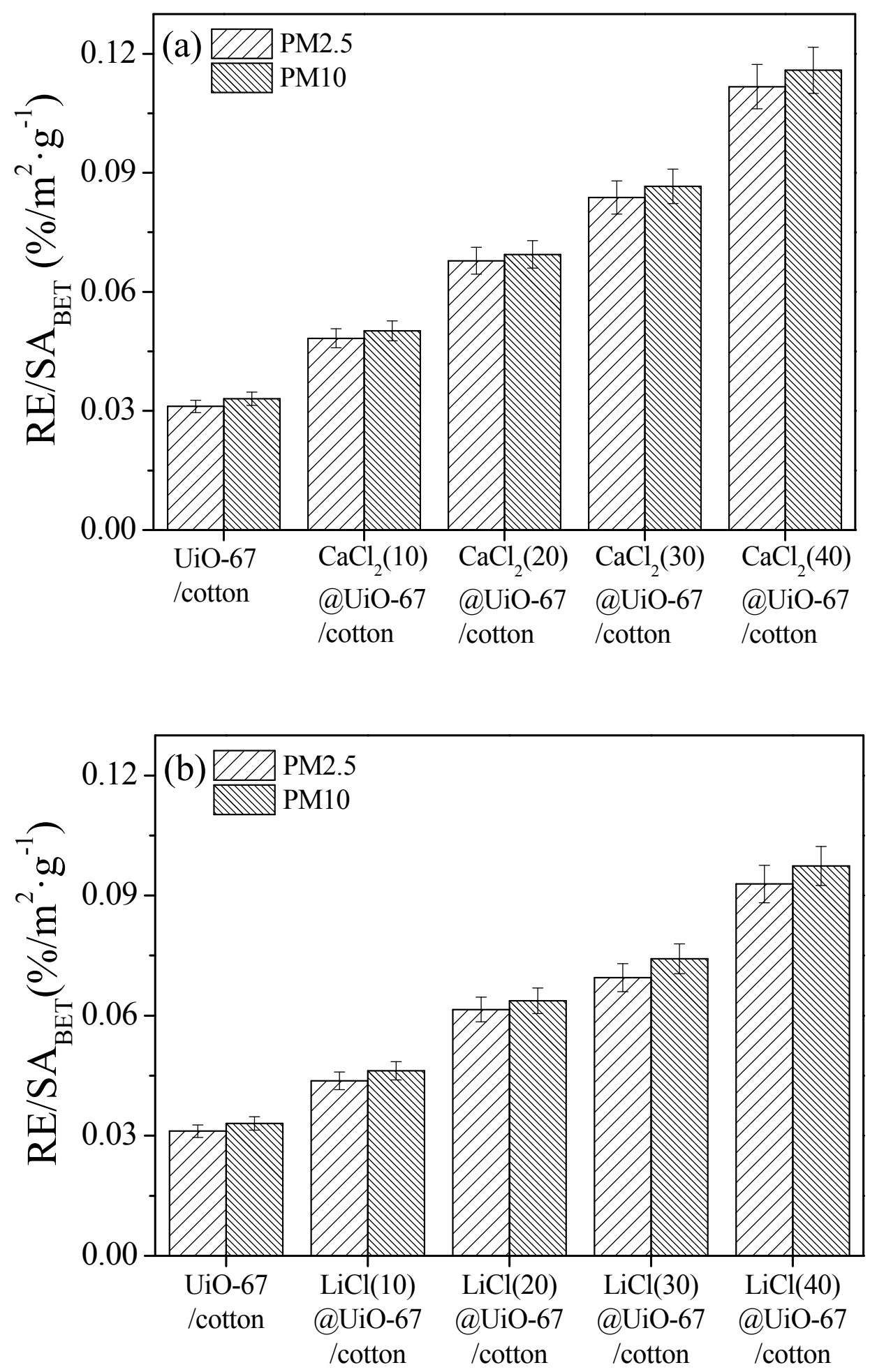

Figure S17. Removal efficiencies (for PM2.5 and PM10) of (a) $\mathrm{CaCl}_{2} @$ UiO-67s/cotton and (b) LiCl@UiO-67s/cotton, based on unit surface area of UiO-67s, after filtration for $60 \mathrm{~min}$. 

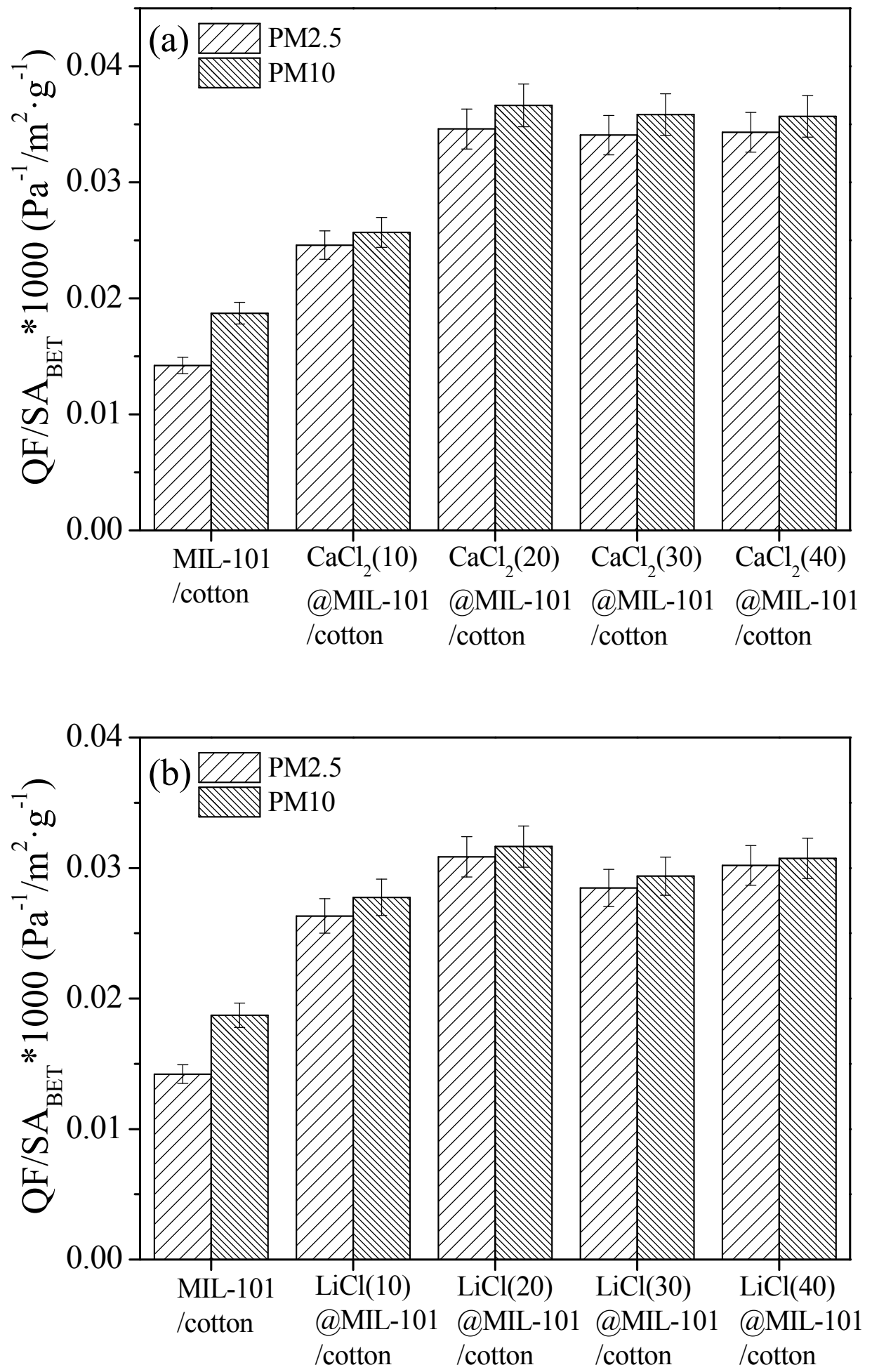

Figure S18. Quality factors (for PM2.5 and PM10) of (a) $\mathrm{CaCl}_{2} @ \mathrm{MIL}-101 \mathrm{~s} /$ cotton and (b) LiCl@MIL-101s/cotton, based on unit surface area of MIL-101s, after filtration for 60 min. 

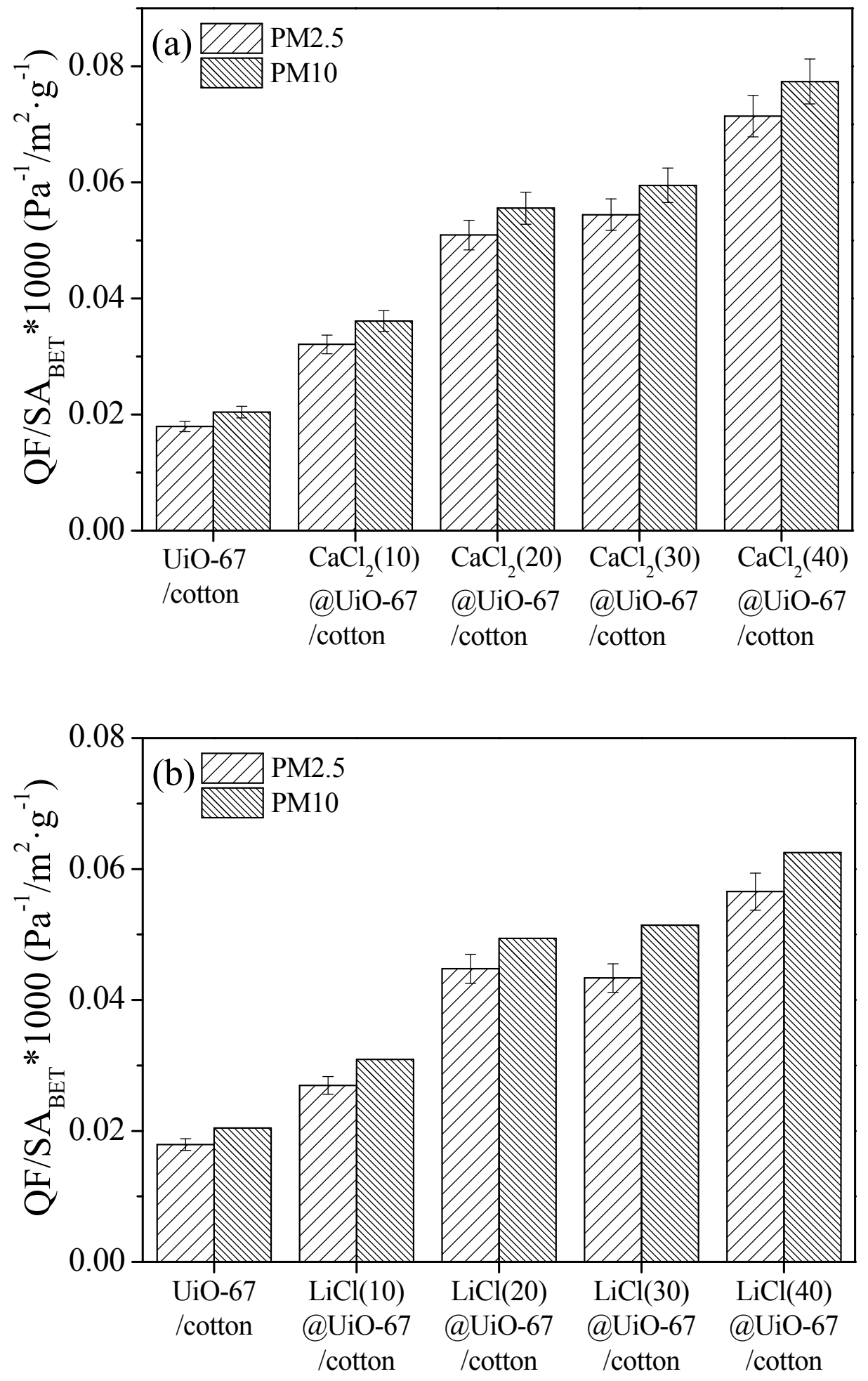

Figure S19. Quality factors (for PM2.5 and PM10) of (a) $\mathrm{CaCl}_{2} @ \mathrm{UiO}-67 \mathrm{~s} /$ cotton and (b) LiCl@UiO-67s/cotton, based on unit surface area of UiO-67s, after filtration for $60 \mathrm{~min}$. 

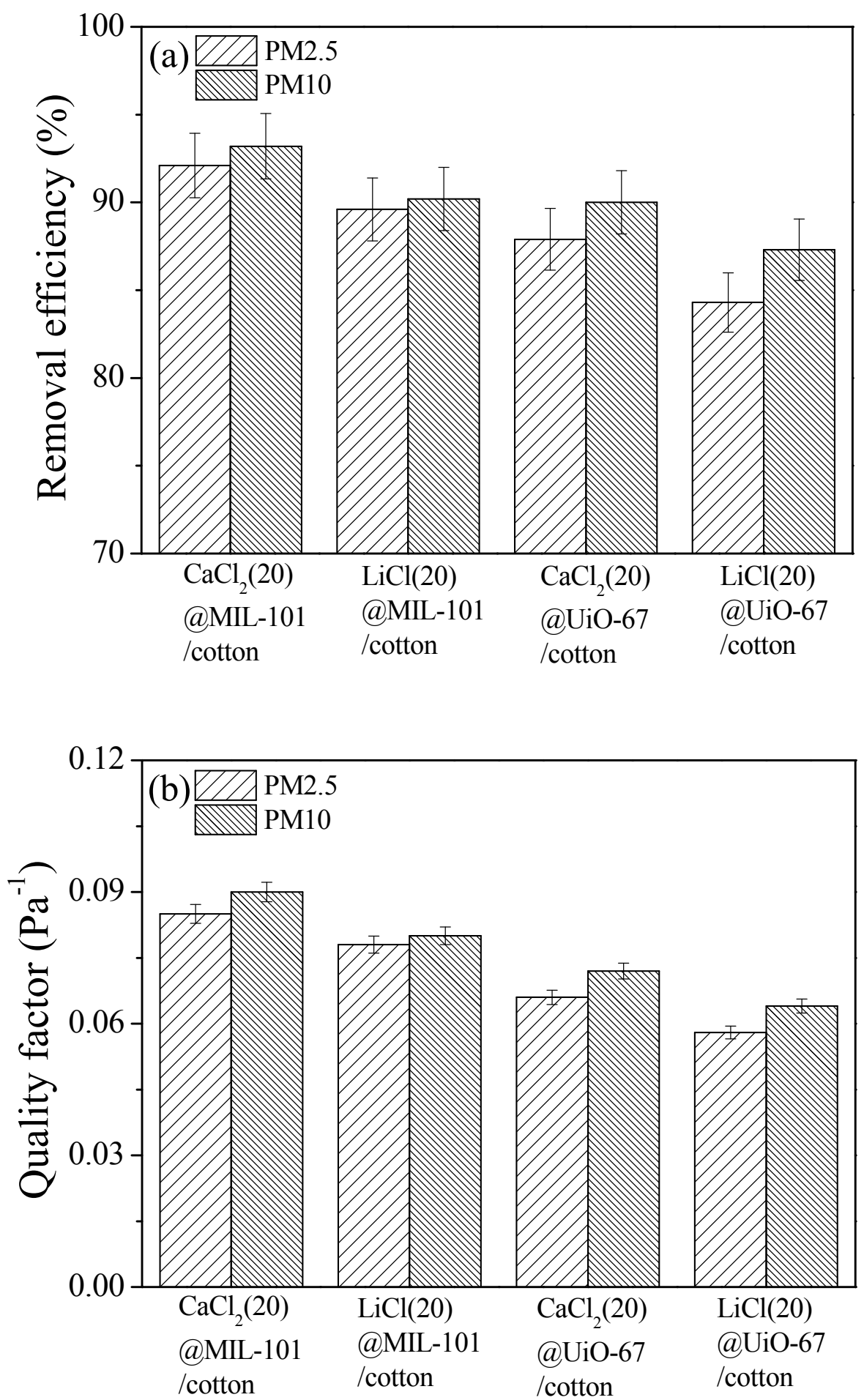

Figure S20. (a) Removal efficiencies and (b) quality factors of IS(20)@MOFs/cotton. 


\section{References}

[1] Khan, N. A.; Jhung, S. H. Phase-Transition and Phase-Selective Synthesis of Porous Chromium-Benzenedicarboxylates. Cryst. Growth Des. 2010, 10, 1860-1865.

[2] Katz, M. J.; Brown, Z. J.; Coloón, Y. J.; Siu, P. W.; Scheidt, K. A.; Snurr, R. Q.; Hupp, J. T.; Farha, O. K. A facile synthesis of UiO-66, UiO-67 and their derivatives. Chem. Commun. 2013, 49, 9449-9451.

[3] Permyakova, A.; Wang, S.; Courbon, E.; Nouar, F.; Heymans, N.; D'Ans, P.; Barrier, N.; Billemont, P.; Weireld, G.D.; Steunou N.; Serre, C. Design of salt-metal organic framework composites for seasonal heat storage applications. J. Mater. Chem. A 2017, 5, 12889-12898.

[4] Zhang, Y.; Xiong, J.; Chen, C.; Li, Q.; Liu, J.; Zhang, Z. Regulating the dissociation of $\mathrm{LiCl}$ and transportation of $\mathrm{Li}$ ions within $\mathrm{UiO}-66-\mathrm{NH}_{2}$ framework for humidity sensing applications with superb comprehensive performances. J. Alloys Compd. 2020, 18, 152854.

[5] Yoo, D. K.; Woo H. C.; Jhung, S. H. Effective removal of particulate matter from air by using zeolite-coated filters. J. Mater. Chem. A 2020, 8, 17960-17968.

[6] Amedi, H. R.; Aghajani, M. Aminosilane-functionalized ZIF-8/PEBA mixed matrix membrane for gas separation application. Micropor. Mesopor. Mater. 2017, 247, 124-135. 